www.jmscr.igmpublication.org

Impact Factor 5.84

Index Copernicus Value: 71.58

ISSN (e)-2347-176x ISSN (p) 2455-0450

crossref DOI:_https://dx.doi.org/10.18535/jmscr/v5i10.112

Journal Of Medical Science And Clinical Research

\title{
Numerical and Visual Analog Scale for Assessment of Clinical Pain in Indian Population
}

\author{
Authors \\ Dr V N Vaid ${ }^{1}$, Shipra Singh ${ }^{2}$, Dr Pankaj Mishra ${ }^{3}$, Dr K G Rao ${ }^{4}$
}

${ }^{1}$ Associate Professor Anaesthesia, Mayo Institute of Medical Sciences, Barabanki, Lucknow, U.P

${ }^{2}$ Assistant Professor Anaesthesia, Mayo Institute of Medical Sciences, Barabanki, Lucknow, U.P

${ }^{3}$ Prof., Dept of Social \& Preventive Medicine, Mayo Institute of Medical Sciences, Barabanki, Lucknow U.P

${ }^{4}$ Associate Professor Anaesthesia, Mayo Institute of Medical Sciences, Barabanki, Lucknow, U.P

Corresponding Author

Dr Shipra Singh

202/A, Insaf Nagar, Indranagar, Lucknow-226016, U.P., India

\begin{abstract}
Background: Numerous pain measurement scales have been evolved but not all have reliable outcome and cannot be used easily in all patients. The present study was done to assess the effect of literacy on ability to respond to the pain rating scales.

Materials \& Methods: The present study was conducted in the department of anesthesiology in year 2016. It included 150 patients undergoing surgical procedures in surgery, obstetrics and gynecology, ENT, urology or neurosurgery. Intraoperative anaesthetic care was standardized to the type of the anaesthesia (general, spinal, blocks). Patients were asked to rate their current pain intensity on VAS scale from 0 to 10 where 0 indicated no pain and 10 indicated the worst pain.

Similarly, for rating pain on the numeric analog scale, patients were asked to rate their current pain intensity on NAS scale from 0 to 100 where 0 indicated no pain and 100 indicated the worst pain. The pain rating was taken exactly 24 hours after completion of surgery.

Results: Out of 150 patients, males were 75 and females were 75 . The difference was non-significant (P-1). Under general surgery, 45 patients responded to VAS while 12 not, O.B.G (35 responded, 10 not), orthopaedics ((35 responded, 6 not), others (20 responded, 7 not). Surgery < 30 minutes (12 responded, 3 not), 30 mins -2 hours (102 responded, 32 not), > 2hours (1 responded). Type of anaesthesia used was general anaesthesia (5 responded), spinal (40 responded, 20 not), epidural (30 responded, 5 not), local (25 responded, 5 not), block (15 responded, 5 not). Under general surgery, 45 patients responded to NAS while 11 not, O.B.G (45 responded, 12 not), orthopaedics (25 responded, 8 not), others (18 responded, 6 not). Surgery < 30 minutes (11 responded, 4 not), 30 mins -2 hours (100 responded, 31 not), > 2hours (2 responded, 2 not). Type of anaesthesia used was general anaesthesia (4 responded, 1 not), spinal (38 responded, 22 not), epidural (28 responded, 6 not), local (27 responded, 3 not), block (20 responded, 5 not). The difference was non- significant $(P>0.05)$.

Patients who responded to VAS were from upper (20), middle (80) and lower class (50). Those who responded to NAS were from upper (10), middle (70) and lower class (70). Their education level was primary (90), secondary (10) and illiterate (50) on VAS and primary (90), secondary (20) and illiterate (40) on NAS. The difference was significant $(P<0.05)$.

Conclusion: Numerous pain assessment scales are available, none are reliable. Visual analog scale and numeric analog scales are simple to perform tools for assessment of pain in Indian rural population, even illiterate patients can easily rate their pain on these scales.

Keywords: Numerical analog scale, Pain, Visual analog scale.
\end{abstract}




\section{Introduction}

Pain is defined as an unpleasant emotional and sensory experience with actual or potential tissue damage, or described in terms of such damage. In order to assess the pain, there has to be reliable method. Numerous pain measurement scales have been evolved but not all have reliable outcome and cannot be used easily in all patients. Demonstration of pain varies from patient to patient. There is need of various methods of pain assessment. ${ }^{1}$

Various authors have conducted the study and found that about 7 to $11 \%$ of people are unable to complete the visual analog scale or find it confusing. Moreover, studies are needed to evaluate the applicability of these scales in India. Patient can reply to pain assessment methods only when they are literate enough to understand and respond to the scale. According to recent data published by government of India, only $74 \%$ of the Indian population is literate, while $26 \%$ is illiterate. $^{2}$ The literacy rate is even lower for females, where illiteracy affects $35 \%$ of the Indian population. It is further depends on the area, urban being more literacy rate than the rural one.

The visual analogue scale or visual analog scale (VAS) is a psychometric response scale which can be used in questionnaires. It is a measurement instrument for subjective characteristics or attitudes that cannot be directly measured. When responding to a VAS item, respondents specify their level of agreement to a statement by indicating a position along a continuous line between two end-points. $^{3}$

The literature shows that numerical rating scale (NRSs) provide sufficient discriminative power for chronic pain patients to describe their PI. Invariably, authors either report that the NRS and VAS are equally efficient for assessment of cancer pain; that the NRS may be preferred for assessment of PI in chronic nonmalignant pain in the clinic because of ease of use and standardized format; and that the NRS is preferred by the majority of patients in different cultures. ${ }^{4}$ The present study was done to assess the effect of literacy on ability to respond to the pain rating scales.

\section{Materials \& Methods}

The present study was conducted in the department of anesthesiology in year 2016. It included 150 patients undergoing surgical procedures in surgery, obstetrics and gynecology, ENT, urology or neurosurgery. All were informed regarding the study and written consent was obtained. Ethical clearance was taken from institutional ethical committee.

Intraoperative anaesthetic care was standardized to the type of the anaesthesia (general, spinal, blocks). All patients were provided injection paracetamol $1000 \mathrm{mg}$ every $8^{\text {th }}$ hourly and injection tramadol $50 \mathrm{mg}$ every 8th hourly.

To evaluate pain on the visual analog scale, patients were given a ruler marked from 0 to 10 , where ever. Patients were asked to rate their current pain intensity on VAS scale from 0 to 10 where 0 indicated no pain and 10 indicated the worst pain.

Similarly, for rating pain on the numeric analog scale, patients were asked to rate their current pain intensity on NAS scale from 0 to 100 where 0 indicated no pain and 100 indicated the worst pain. The pain rating was taken exactly 24 hours after completion of surgery. This is one time assessment and rating was taken at rest. Readings on both scales were taken immediately, one after the other with a time gap of no more than five minutes.

Results were tabulated and subjected to statistical analysis for correct inference. $\mathrm{P}$ value $<0.05$ was considered significant.

\section{Results}

Table I shows that out of 150 patients, males were 75 and females were 75 . The difference was nonsignificant (P-1). Table II shows that under general surgery, 45 patients responded to VAS while 12 not, O.B.G (35 responded, 10 not), orthopaedics ((35 responded, 6 not), others (20 responded, 7 not). Surgery $<30$ minutes $(12$ 
responded, 3 not), 30mins - 2 hours (102 responded, 32 not), > 2hours (1 responded). Type of anaesthesia used was general anaesthesia (5 responded), spinal (40 responded, 20 not), epidural (30 responded, 5 not), local (25 responded, 5 not), block (15 responded, 5 not). Under general surgery, 45 patients responded to NAS while 11 not, O.B.G (45 responded, 12 not), orthopaedics (25 responded, 8 not), others (18 responded, 6 not). Surgery < 30 minutes $(11$ responded, 4 not), 30mins - 2 hours (100 responded, 31 not), > 2hours (2 responded, 2 not). Type of anaesthesia used was general anaesthesia (4 responded, 1 not), spinal (38 responded, 22 not), epidural (28 responded, 6 not), local (27 responded, 3 not), block (20 responded, 5 not). The difference was non- significant $(\mathrm{P}>0.05)$.

Graph I shows that patients who responded to Vas from upper (20), middle (80) and lower class (50). Those who responded to NAS was from upper (10), middle (70) and lower class (70). Their education level was primary (90), secondary (10) and illiterate (50) on VAS and primary (90), secondary (20) and illiterate (40) on NAS. The difference was significant $(\mathrm{P}<0.05)$.

Table I Distribution of Patients

\begin{tabular}{|l|c|c|}
\hline \multicolumn{3}{|l|}{ Total- 150 } \\
\hline Male & Females & P value \\
\hline 75 & 75 & 1 \\
\hline
\end{tabular}

Table II Surgical characteristics and ability to rate pain on VAS and NAS

\begin{tabular}{|c|c|c|c|c|c|c|}
\hline & $\begin{array}{c}\text { Able to rate on } \\
\text { VAS }\end{array}$ & $\begin{array}{c}\text { Unable to rate on } \\
\text { VAS }\end{array}$ & $\mathrm{P}$ value & $\begin{array}{c}\text { Able to rate on } \\
\text { NAS }\end{array}$ & $\begin{array}{c}\text { Unable to rate on } \\
\text { NAS }\end{array}$ & $\mathrm{P}$ value \\
\hline Type of surgery & & & \multirow[t]{5}{*}{0.711} & & & \multirow[t]{5}{*}{0.24} \\
\hline G.S & 45 & 12 & & 45 & 11 & \\
\hline O.B.G & 35 & 10 & & 45 & 12 & \\
\hline Orthopae & 35 & 6 & & 25 & 8 & \\
\hline Others & 20 & 7 & & 18 & 6 & \\
\hline Duration & & & \multirow[t]{4}{*}{0.5} & & & \multirow[t]{4}{*}{0.45} \\
\hline$<30$ mins & 12 & 3 & & 11 & 4 & \\
\hline $30-2$ hrs & 102 & 32 & & 100 & 31 & \\
\hline$>2 \mathrm{hrs}$ & 1 & 0 & & 2 & 2 & \\
\hline Type of anesthesia & & & \multirow[t]{6}{*}{0.6} & & & \multirow[t]{6}{*}{0.32} \\
\hline General & 5 & 0 & & 4 & 1 & \\
\hline Spinal & 40 & 20 & & 38 & 22 & \\
\hline Epidural & 30 & 5 & & 28 & 6 & \\
\hline Block & 15 & 5 & & 20 & 5 & \\
\hline Total & 115 & 35 & & 113 & 37 & \\
\hline
\end{tabular}

Graph I Baseline characteristics on VAS and NAS

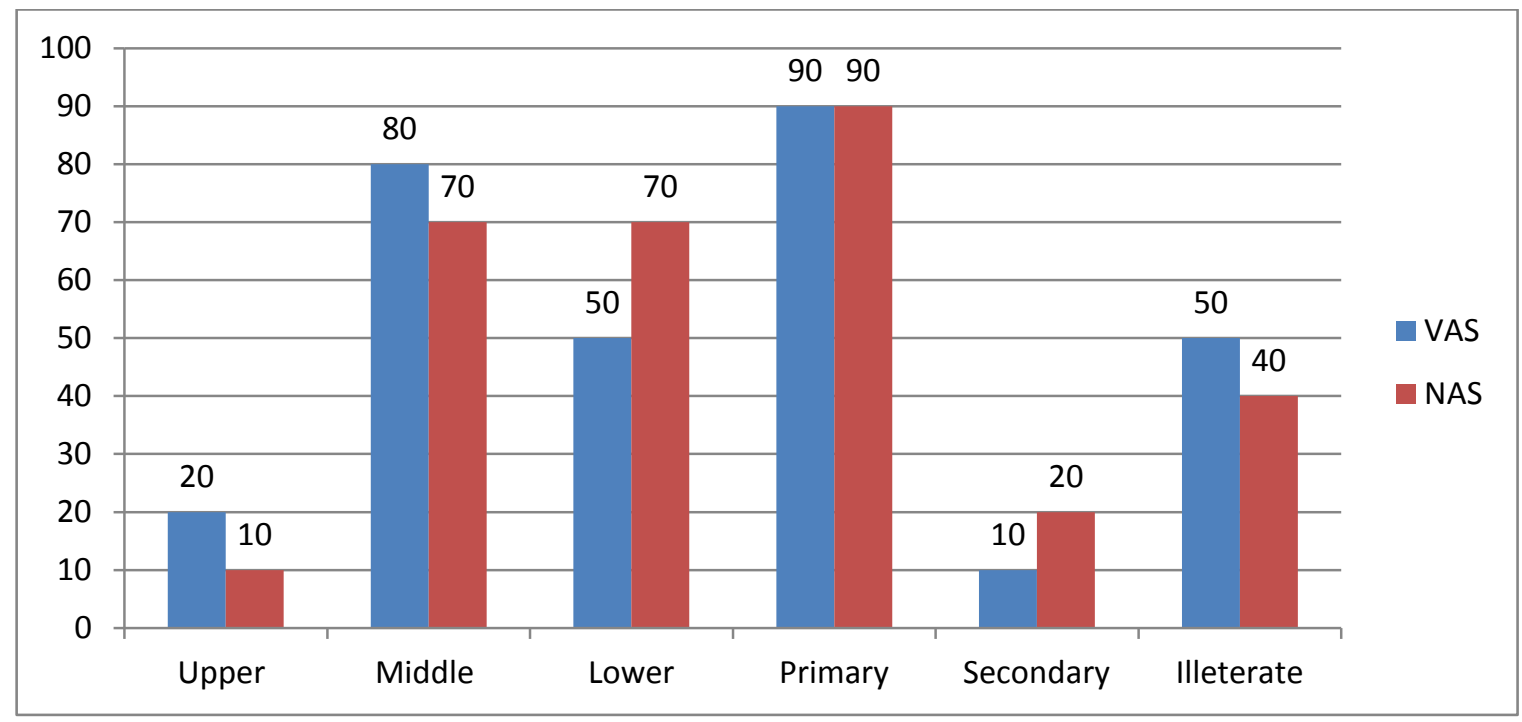




\section{Discussion}

The efficient clinical management of pain is based on its correct diagnosis. This entails a comprehensive evaluation of patient's pain and such assessments rely in part on the use of accurate evaluation tools.

Many studies have been done so far who shows multiple clinical pain assessment scales. Measures of pain are primarily classified into behavioral and subjective. There is an extensive literature regarding the use of Numerical Rating Scales (NRSs), Verbal Rating Scales (VRSs), and Visual Analogue Scales (VASs) dating from the 1950s. Nearly all of this literature is from the social sciences, notably census and surveys, public opinion polls, and marketing research. ${ }^{5}$ The present study was done to assess the effect of literacy on ability to respond to the pain rating scales.

In our study, out of 150 patients, males were 75 and females were 75 . Under general surgery, 45 patients responded to VAS while 12 not, O.B.G (35 responded, 10 not), orthopaedics ((35 responded, 6 not), others (20 responded, 7 not). This is similar to Scott $\mathbf{J}$ et al. ${ }^{6}$

Surgery which lasted $<30$ minutes (12 responded, 3 not), 30mins - 2 hours (102 responded, 32 not), $>2$ hours (1 responded). Type of anaesthesia used was general anaesthesia (5 responded), spinal (40 responded, 20 not), epidural (30 responded, 5 not), local (25 responded, 5 not), block (15 responded, 5 not). This is similar to the results of Prince et al. $^{7}$

Similarly when we compared VAS with NAs, under general surgery, 45 patients responded to NAS while 11 not, O.B.G (45 responded, 12 not), orthopaedics (25 responded, 8 not), others (18 responded, 6 not). Surgery $<30$ minutes (11 responded, 4 not), 30mins - 2 hours (100 responded, 31 not), > 2hours (2 responded, 2 not). Type of anaesthesia used was general anaesthesia (4 responded, 1 not), spinal (38 responded, 22 not), epidural (28 responded, 6 not), local (27 responded, 3 not), block (20 responded, 5 not). This is similar to the results of Sloman et al. ${ }^{8}$
We assess the socio economic status of patients. Patients who responded to Vas were from upper (20), middle (80) and lower class (50). Those who responded to NAS were from upper (10), middle (70) and lower class (70). Their education level was primary (90), secondary (10) and illiterate (50) on VAS and primary (90), secondary (20) and illiterate (40) on NAS. This is similar to Gagliese et al. ${ }^{9}$

\section{Conclusion}

Numerous pain assessment scales are available, none are reliable. Visual analog scale and numeric analog scales are simple to perform tools for assessment of pain in Indian rural population, even illiterate patients can easily rate their pain on these scales.

\section{References}

1. Ferrell BA, Ferrell BR, Rivera L. Pain in cognitively impaired nursing home patients. J Pain Symptom Manage 1995;10: 591-8.

2. Bergeron DA, Leduc G, Marchand S, Bourgault P. Descriptive study of the postoperative pain assessment and documentation process in a university hospital. Pain Res Manag. 2011; 16: 81-6.

3. Kremer E, Atkinson JH, Ignelzi RJ. Measurement of pain. Pain. 1981;10: 2418.

4. Revill SI, Robinson JO, Rosen M, Hogg MI. The reliability of a linear analogue for evaluating pain. Anaesthesia 1976; 31: 1191- 8.

5. Hartrick CT, Kovan JP, Shapiro S. The numeric rating scale for clinical pain measurement: A ratio measure? Pain Pract. 2003; 3: 310-6.

6. Scott J, Huskisson EC. Graphic representation of pain. Pain. 1976;2:175-84.

7. Price DD, McGrath PA, Rafii A, Buckingham B. The validation of visual analogue scales as ratio scale measures for 
chronic and experimental pain. Pain. 1983;17:45-56.

8. Sloman R, Rosen G, Rom M, Shir Y. Nurses' assessment of pain in surgical patients. J Adv Nurs. 2005; 52:125-32.

9. Gagliese L, Weizblit N, Ellis W, Chan VW. The measurement of postoperative pain: A comparison of intensity scales in younger and older surgical patients. Pain 2005;117:412-20. 